\title{
O conceito de letramento multimodal crítico na escola: o que dizem os professores de inglês ${ }^{1}$ \\ The concept of critical multimodal literacy at school: what the English teachers say
}

\author{
Daiane Aline Kummer*
}

\begin{abstract}
RESUMO: Para uma participação bemsucedida em sociedade, precisamos de conhecimentos de letramento multimodal crítico (LMC), ou seja, conhecimentos sobre a combinação crítica e reflexiva de diferentes recursos semióticos, em especial, destacamos os visuais, em diferentes gêneros discursivos. A escola tem papel fundamental no desenvolvimento de conhecimentos de LMC pelos estudantes, para tanto, o objetivo deste trabalho é verificar como professores de inglês recontextualizam esses conhecimentos na escola. Neste estudo, tomamos como base teórica e metodológica a Análise Crítica de Gênero (MOTTA-ROTH, 2008a), e como corpus respostas a entrevistas de professores de inglês de escolas públicas de Santa Maria, Brasil. A análise das respostas às entrevistas revela que a necessidade de conhecer e de mobilizar os recursos semióticos ao agir socialmente é reconhecida pelos professores. Porém, o elemento crítico do conceito de LMC não é enfocado, o que indica a necessidade de refletirmos sobre nosso papel como professores de inglês, no sentido de possibilitar aos estudantes conhecimentos para a combinação de distintos recursos semióticos em diferentes gêneros e contextos de maneira crítica e reflexiva.
\end{abstract}

PALAVRAS-CHAVE: Recursos semióticos visuais. Letramento multimodal crítico. Professores de inglês.

\begin{abstract}
In order to have a successful participation in society, knowledge of critical multimodal literacy (CML) is needed, that is, knowledge about the critical and reflexive combination of different semiotic resources, in special, we highlight the visual ones, in different discursive genres. The school has a fundamental role in the development of CML knowledge by students, in this sense, the objective of this study is to verify how English teachers recontextualize this knowledge at schools. In this study, we have as theoretical and methodological basis the Critical Genre Analysis ((MOTTA-ROTH, 2008a) and as corpus, interviews answers of English teachers from public schools of Santa Maria, Brazil. The analysis of the answers from the interviews reveals that the need to promote and mobilize the semiotic resources while socially acting is recognized by the teachers. However, the critical element of the concept is not focused, that indicates the need to reflect about our role as English teachers, in the sense of making possible to students to know how to combine different semiotic resources in different genres and contexts in a critical and reflective way.
\end{abstract}

KEYWORDS: Visual semiotic resources. Critical multimodal literacy. English teachers.

\footnotetext{
1 Este trabalho apresenta um recorte da minha dissertação de mestrado (KUMMER, 2015), orientada pela professora Graciela Rabuske Hendges e vinculada ao Programa de Pós-Graduação em Letras da Universidade Federal de Santa Maria (UFSM).

*Doutoranda em Estudos Linguísticos no Programa de Pós-Graduação em Letras da UFSM.
} 


\section{Introdução}

Diversos estudos no âmbito internacional, Kress (1997), Cope e Kalantzis (2000), Jewitt e Kress (2003), Bezemer e Kress (2010), Jewitt (2011), e também, no âmbito nacional, Hendges (2006), Nascimento (2012), Florek (2015), Hemais (2015), Marques (2015), Predebon (2015), para citar alguns, destacam a necessidade de reconhecer e considerar os diferentes recursos semióticos integrados nos gêneros discursivos. Isso se justifica pelo fato de que, apesar de os gêneros discursivos incluírem diferentes recursos semióticos, essa inclusão tem sido facilitada, em virtude, principalmente, dos avanços da tecnologia, (THE NEW LONDON GROUP, 1996; COPE; KALANTZIS; 2000; KRESS; VAN LEEUWEN, 2006), acarretando transformações profundas nos gêneros.

Devido a essas transformações, o estudo sobre como os diferentes recursos semióticos se apresentam e se articulam nos textos é essencial no intuito de promover o desenvolvimento de conhecimentos para reconhecer e combinar esses distintos recursos semióticos, em outras palavras, o desenvolvimento de letramento multimodal (JEWITT; KRESS, 2003). Contudo, considerando que os textos são imbuídos de valores e ideologias (CERVETTI; PARDALES; DAMICO, 2001; MOTTA-ROTH, 2008a), o reconhecimento e a combinação de diferentes recursos semióticos precisam ser realizados de maneira consciente e crítica. Isto posto, propomos a necessidade de desenvolver conhecimentos de letramento multimodal crítico (LMC). Acrescentamos o termo crítico a fim de enfatizar a necessidade do desenvolvimento de conhecimentos relacionados à reflexão e consciência ao interagir discursivamente. Em resumo, o conceito de $\mathrm{LMC}^{2}$ envolve conhecimentos sobre a combinação crítica e reflexiva de diferentes recursos semióticos em diversos gêneros discursivos.

Os conhecimentos de LMC nos possibilitam, por exemplo, construir significados, reconhecer a organização retórica de determinado gênero e ainda identificar diferentes pontos de vistas presentes nos textos a partir do reconhecimento dos diferentes recursos semióticos. Com base nessas possibilidades, dada a posição central da escola na formação dos estudantes, destacamos o papel dos professores no sentido de guiar/encorajar estudantes no desenvolvimento desses conhecimentos, auxiliando-os no reconhecimento dos diferentes recursos semióticos, assim como, no reconhecimento das possibilidades e limitações (KRESS,

\footnotetext{
${ }^{2}$ Esse conceito está sendo estudado e discutido no grupo de pesquisa orientado pela professora Graciela Rabuske Hendges, do Programa de Pós-Graduação em Letras da UFSM, podendo ser verificado também em outros trabalhos do grupo, como Predebon (2015) e Florek (2015).
} 
1997) desses recursos na comunicação. Além disso, a partir de uma perspectiva multimodal crítica, os estudantes podem desenvolver conhecimentos para interagir de maneira consciente nas variadas práticas sociais de que participam.

O professor é a peça central no processo de ensino, é ele que medeia a relação/contato do aluno com o material didático que utiliza e, consequentemente, com os conteúdos, conceitos, princípios e ideologias desse material, sendo importante entender sua atitude frente a esse processo. Uma vez que o professor é o sujeito responsável por possibilitar e motivar o desenvolvimento de conhecimentos de LMC na escola, neste trabalho, investigamos como professores entendem esse conceito, verificando se e como conhecimentos de LMC são abordados nesse contexto e, ainda, qual é o papel do livro didático nessa recontextualização, segundo os professores.

Em outras palavras, dada a necessidade de conhecimentos para interagir criticamente reconhecendo e mobilizando os diferentes recursos semióticos dos gêneros e, ainda, visto o papel central do professor no desenvolvimento desses conhecimentos, o objetivo principal deste estudo é verificar como professores de inglês recontextualizam o conceito de LMC na escola a partir do livro didático adotado e/ou de outros materiais didáticos que utiliza.

Para tanto, na próxima seção, apresentamos os pressupostos teóricos que embasam este trabalho.

\section{Pressupostos teóricos}

\subsection{Conceitos gerais}

Este trabalho tem como base teórica e metodológica a Análise Crítica de Gênero (ACG), perspectiva que visa à "análise de elementos lingüísticos e retóricos do texto (como na Análise de Gênero estrita) em combinação com a análise dos elementos ideológicos do contexto (como a Análise do Discurso Crítica)"3 (MOTTA-ROTH, 2008a, p. 370). A investigação de elementos linguísticos, retóricos e ideológicos de um texto é possível visto a integração de diferentes perspectivas que compõem a ACG (cf. MOTTA-ROTH, 2008a; SCHERER, 2013): Linguística Sistêmico-Funcional (HALLIDAY; HASAN, 1989), Sociorretórica (SWALES, 1990; BAZERMAN, 1988 apud MOTTA-ROTH, 2008a) e Análise Crítica do Discurso (FAIRCLOUGH, 1992; 2003).

\footnotetext{
${ }^{3}$ Todas as citações originalmente publicadas em inglês foram traduzidas pela autora deste trabalho.
} 
Nessa perspectiva, a linguagem entendida como constituída por diferentes níveis ou estratos, como inicialmente proposto por Halliday e Matthiessen (2014[1994]). Esses níveis ou estratos incluem a fonologia/grafologia, a lexicogramática, semântica e pragmática, o registro, o gênero e a ideologia (MOTTA-ROTH, 2008a), como pode ser observado na Figura 1, onde "[c]ada círculo concêntrico recontextualiza os círculos menores e assim subseqüentemente (cf.: Martin 1992:496)" (MOTTA-ROTH, 2008a, p. 353).

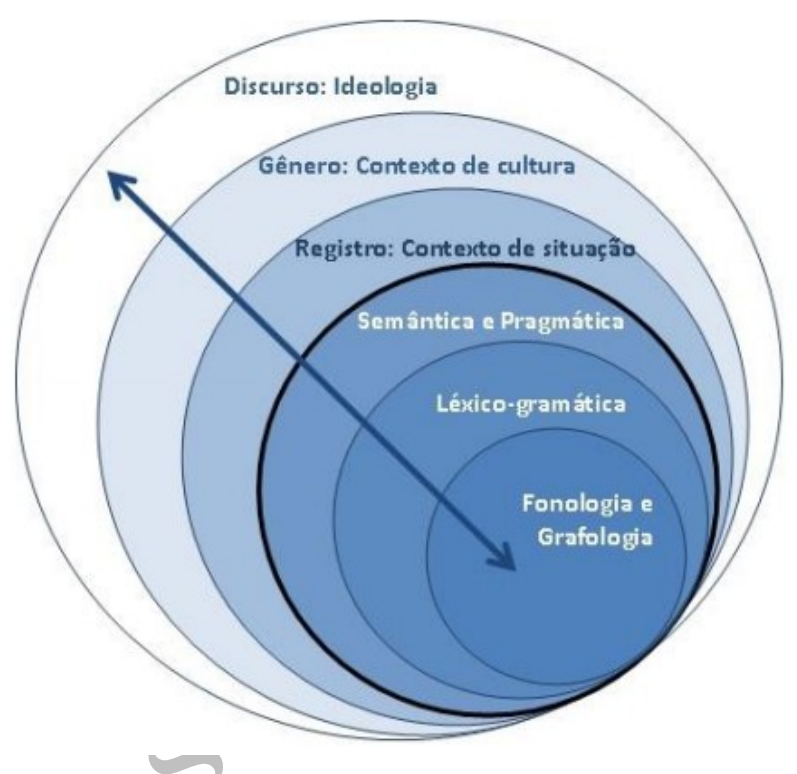

Figura 1. Estratificação dos planos comunicativos. Fonte: Motta-Roth, 2008a, p. 352 apud Scherer, 2013, p. $39^{4}$.

Ao interagir discursivamente manipulamos esses diferentes níveis simultaneamente (MEURER, 2011) e o fizemos por meio de gêneros. Entendemos, então, a linguagem enquanto gênero. Motta-Roth (2011, p. 156) explica que “o conhecimento humano é construído por meio de gêneros - linguagem usada em contextos recorrentes da experiência humana - socialmente compartilhados". A autora (MOTTA-ROTH, 2008a, p. 353) especifica que o "gênero é uma conformação de significados recorrentes, organizada em estágios e orientada para o objetivo de realizar práticas sociais (cf.:Martin 2002: 269)"”.

Os gêneros são produzidos a partir da combinação de "escolhas variadas disponíveis historicamente entre os diferentes modos de significado" (THE NEW LONDON GROUP, 2000, p. 29), em outras palavras, os gêneros envolvem "uma interação complexa de texto

\footnotetext{
${ }^{4}$ Figura proposta por Motta-Roth (2008a), a partir da adaptação de Martin (1992, p. 496) e de Hendges (2005, p.
} $6)$. 
escrito, imagens e outros elementos gráficos ou sonoros, organizados em entidades coerentes a partir do layout" (KRESS; VAN LEEUWEN, 2006, p. 17). Em vista da diversidade de elementos, mais especificamente, recursos semióticos, que podem ser incluídos nos textos, os gêneros podem ser reconhecidos como multimodais (VAN LEEUWEN, 2005).

Na próxima seção, apresentamos os pressupostos teóricos relacionados ao caráter multimodal dos gêneros.

\subsection{Letramento multimodal crítico}

Para Nascimento (2012, p. 29), "as pessoas constroem significados e se comunicam através de uma variedade de recursos que podem incluir, mas vão além da linguagem verbal". Essa perspectiva refuta a premissa de que a linguagem verbal seja central em qualquer texto, Kress (1997, p. 60), por exemplo, explica que "a comunicação sempre foi multissemiótica" e Jewitt e Kress (2003) corroboram essa visão propondo que "não existe uma comunicação monomodal" (2003, p. 2). Desse modo, ao interagir discursivamente fazemos uso de diferentes recursos semióticos (a imagem, a escrita, layout, música, gesto, fala e outros (KRESS, 2011)) e, apesar de um texto escrito em que a linguagem verbal escrita pareça o único recurso semiótico empregado, há outros recursos como tamanho, tipo, cor da fonte e espaçamento que têm implicações para o significado no texto, resultando em um texto multimodal.

Considerar que diferentes recursos semióticos são incluídos em uma dada situação discursiva é reconhecer a necessidade de conhecimentos para identificar esses recursos, e, assim, ler e produzir textos que incluam distintos e diversos recursos semióticos. Ao abordar esses conhecimentos, estamos falando do conceito de letramento multimodal (COPE, KALANTZIS, 2000).

Acrescentado a isso, Cervetti, Pardales e Damico (2001) destacam que ideologias e relações de poder podem estar imbuídas nos diferentes gêneros, materializadas tanto em recursos semióticos verbais quanto em recursos semióticos visuais. Sendo assim, como já destacado na Introdução, explicitamos o termo "crítico" a fim de enfatizar a necessidade de saberes de letramento crítico (CERVETTI; PARDALES; DAMICO, 2001) ao ler e produzir textos a partir da combinação de diferentes recursos semióticos. Para tanto propomos o conceito de letramento multimodal crítico (LMC), também discutido nos estudos de Predebon (2015) e Florek (2015). 
A lista de conhecimentos de LMC, apresentada no Quadro 1, originalmente apontada por Catto (2014), retoma a ideia de que ao interagir discursivamente, os estratos da linguagem são empregados ao mesmo tempo (MEURER, 2011). As diferentes escolhas linguísticas (no nível do texto), considerando as possibilidades e restrições dos diferentes recursos semióticos, produzem diferentes significados e perpetuam diferentes pontos de vista (no nível do contexto).

No contexto escolar, os alunos carecem de LMC para que possam, não apenas reconhecer os múltiplos recursos semióticos que constituem determinado gênero discursivo, mas interagir utilizando e produzindo esses recursos, além de "desenvolver a capacidade de se manifestar, negociar" (THE NEW LONDON GROUP, 2000, p. 13) nas diversas situações de que participam.

Quadro 1. Conhecimentos contemplados no conceito de letramento multimodal crítico.

Conhecer, selecionar e combinar de maneira informada e qualificada (ou seja, situada/contextualizada) os diversos recursos semióticos

a) no nível grafológico/fonológico/gráfico, mobilizando o processo de expressão (palavra - verbal; linha diagonal - visual);

b) no nível lexicogramatical, mobilizando as potencialidades do sistema linguístico - verbal (por exemplo, o sistema de modo) e visual (por exemplo, o sistema de distância social);

c) no nível semântico e pragmático, mobilizando o processo de produção de sentido (significados interpessoais (verbal) e/ou significados interativos (visual));

d) no nível do registro, mobilizando particularidades do contexto de situação (campo, relação e modo);

e) no nível do gênero, mobilizando configurações textuais e contextuais recorrentes (propósito comunicativo, por exemplo);

f) no nível ideológico, mobilizando análise crítica dos diversos Discursos que atravessam os textos (discurso religioso). Fonte: adaptado de Catto (2014, p.4).

Para que os alunos tenham acesso e possam desenvolver os conhecimentos envolvidos pelo LMC, esse conceito precisa ser recontextualizado nas escolas. Documentos oficiais como as Orientaçôes Curriculares Nacionais (OCNs) para o Ensino Médio preveem essa recontextualização ao salientar que "o ensino de letramentos heterogêneos e múltiplos visa a [preparar o aluno] para um futuro desconhecido, para agir em situações novas, imprevisíveis, incertas" (BRASIL, 2006, p. 109). Nesse sentido, reconhecer o papel da escola no desenvolvimento desses conhecimentos pelos alunos é reconhecer a missão da educação de garantir aos alunos a participação na vida pública, comunitária e econômica (THE NEW LONDON GROUP, 1996).

Assim sendo, a escola tem a função de permitir o acesso a diversos discursos/conhecimentos especializados aos alunos, leitores não especializados, e isso ocorre 
por meio da recontextualização do discurso especializado para o contexto escolar. De acordo com Motta-Roth (2010, p.162), "a escola atua como campo recontextualizador (que faz a realocação) do discurso teórico-científico". Sendo assim, é a partir do discurso de materiais didáticos e, principalmente, a partir do discurso de professores que o conceito de LMC é recontextualizado para o contexto escolar. Em vista disso é que abordamos os discursos de professores buscando verificar como esse conceito é recontextualizado nos seus contextos de ensino.

Na próxima seção, apresentamos o corpus e as etapas e categorias de análise do presente trabalho.

\section{Metodologia}

Conforme destacamos na seção de Pressupostos Teóricos, este trabalho está teórica e metodologicamente embasado na perspectiva da Análise Crítica de Gênero, entendendo a importância da inter-relação entre texto e contexto. Ao entrevistar professores de inglês com relação ao conceito de LMC, analisamos as respostas às entrevistas com base em elementos semântico-funcionais identificados com base na proposta de Barton (2004), discutida neste capítulo, levando em consideração o contexto situado dos professores que responderam às entrevistas.

Lembramos que o conceito de LMC envolve conhecimentos de combinação de diferentes recursos semióticos, no entanto, no presente estudo enfocamos a combinação de recursos semióticos verbais escritos e de recursos semiótico imagéticos estáticos. Isso se justifica pelo fato de que este trabalho é um recorte da minha dissertação de mestrado que, além de entrevistas com os professores, envolveu a análise de livros didáticos (KUMMER, 2015).

Tendo em vista esse foco, a seguir detalhamos a seleção do corpus do presente estudo e as etapas de pesquisa.

\subsection{Corpus}

O corpus da presente pesquisa é composto por respostas a entrevistas com professores de inglês de escolas públicas estaduais de Santa Maria, Rio Grande do Sul, Brasil. Esses professores foram selecionados a partir de uma verificação prévia realizada durante o desenvolvimento da minha pesquisa de mestrado (KUMMER, 2015). Essa sondagem objetivou averiguar quais das coleções de língua inglesa, oferecidas pelo Programa Nacional do Livro 
Didático (BRASIL, 2014), eram adotadas nas escolas da cidade. Os professores selecionados para serem entrevistados foram aqueles que utilizavam a coleção de livros didáticos adotada pelo maior número de escolas públicas da cidade de Santa Maria, no caso, a coleção de livros didáticos Upgrade (AGA, 2010), adotada em 10 escolas. Desse modo, tínhamos a possibilidade de entrevistar 10 professores. Apesar da boa receptividade das escolas, por questões de horário e tempo, entrevistei sete dos 10 professores de inglês. Essa dimensão da coleta de dados envolvendo participantes foi aprovada pelo Comitê de Ética em Pesquisa da Universidade Federal de Santa Maria sob o n ${ }^{\circ} 4597213.8 .0000 .5346$ (UFSM, 2014).

\subsection{Etapas de pesquisa e categorias de análise}

A partir da identificação de quais escolas poderíamos visitar, propomos uma entrevista semiestruturada, ou seja, propomos questões pré-determinadas (Quadro 2) para seguir no momento das entrevistas. Incluímos questões sobre o uso do livro dídático, a avaliação do papel da linguagem visual, os gêneros trabalhados e o conceito de letramento multimodal/visual. As entrevistas foram gravadas e transcritas de acordo com a necessidade do trabalho.

Quadro 2. Questões para a entrevista.

1. Em que medida você utiliza o livro didático?

2. Como você avalia o papel da linguagem visual (layout, gráficos, tabelas, fotografias, desenhos, etc.?) no livro didático que você utiliza?

3. Que textos (gêneros discursivos) você trabalha em sala de aula?

4. Esses textos contemplam imagens (linguagem visual como gráficos, tabelas, fotografias, desenhos, etc.?)

5. Você acha relevante considerar as imagens que aparecem nos textos? Por quê?

6. Com que frequência yocê explora as imagens do livro didático?

7. Que tipo de perguntas você propõe para seus alunos sobre as imagens?

8. Você conhece o conceito de letramento multimodal e/ou de letramento visual? Em caso afirmativo, como você explicaria o que significa.

Ao iniciar a entrevista, os professores foram questionados com relação à sua formação acadêmica, à escola em que trabalham, à quantidade de turmas, e à sua carga-horária de trabalho semanal. Na sequência, segui as questões pré-estabelecidas. Assim que as entrevistas foram realizadas, analisamos as respostas, observando elementos semântico-funcionais recorrentes relacionadas a tópicos como: - uso do livro didático em sala de aula; - avaliação do papel da linguagem visual no ensino de inglês; - gêneros trabalhados; - tipos de atividades e perguntas propostas que fazem referência a recursos semióticos visuais; - conceito de letramento multimodal/visual. 
Os elementos semântico-funcionais foram identificados com base na proposta de Barton (2004), sendo mapeados indutivamente e estabelecidos após ouvir repetidamente as gravações. Esses elementos foram selecionados porque chamam a atenção em termos de seu uso repetido e padronizado (BARTON, 2004, p. 66). A proposta de Barton (2004) é similar à tradicional análise de gênero proposta por Swales (1990). Ambas as propostas têm como objetivo uma análise detalhada da linguagem na busca por elementos significativos para o que se quer analisar. Assim, os elementos ricos em significação "estão associados a uma convenção de uso e de significado dentro de determinado contexto", sendo definidos como "aquelas marcas que sinalizam a relação entre texto e contexto" (BARTON, 2004, p. 66). Elementos ricos em significação podem ser "qualquer elemento linguístico em um texto ou em um conjunto de textos que sugere a maneira como o significado é incorporado no texto e sua conexão com o contexto" (BARTON, 2004, p. 66). A identificação dos elementos ricos em significação está relacionada à sua recorrência.

Com relação às entrevistas, os elementos foram selecionados em termos de sua relevância para a presente pesquisa, ou seja, no que diž respeito à influência de recursos semióticos visuais em sala de aula para fins de LMC

Na próxima seção, apresentamos os resultados deste estudo.

\section{Resultados}

Como mencionadona Metodologia, sete professores de escolas públicas de Santa Maria foram entrevistados. Com base nessas entrevistas, verificamos que há uma preocupação desses professores com os recursos semióticos visuais dos textos, além de uma tentativa de explorar esses recursos em aula, por meio do livro didático adotado na escola e/ou por meio de materiais extras, incluindo seu próprio material didático. Nesta seção, descrevemos e discutimos os resultados da análise das respostas às entrevistas.

Para iniciar, salientamos a importância das entrevistas com os professores, visto que, apesar do destaque dado a livros e outros materiais didáticos, esses materiais não substituem a presença de um professor, inclusive, é o professor que guia a utilização desses materiais em sala de aula (TICKS, 2003). Ao tratar do tópico Uso do livro didático em sala de aula percebemos essa importância do professor, visto que apesar da adoção de um livro didático oferecido pelo PNLD, não necessariamente o professor se baseia inteiramente nesse material, 
podendo adaptar ou ainda produzir seu próprio material. Verificamos isso no Gráfico 1, que apresenta o resultado das entrevistas com os professores com relação ao uso do livro didático.

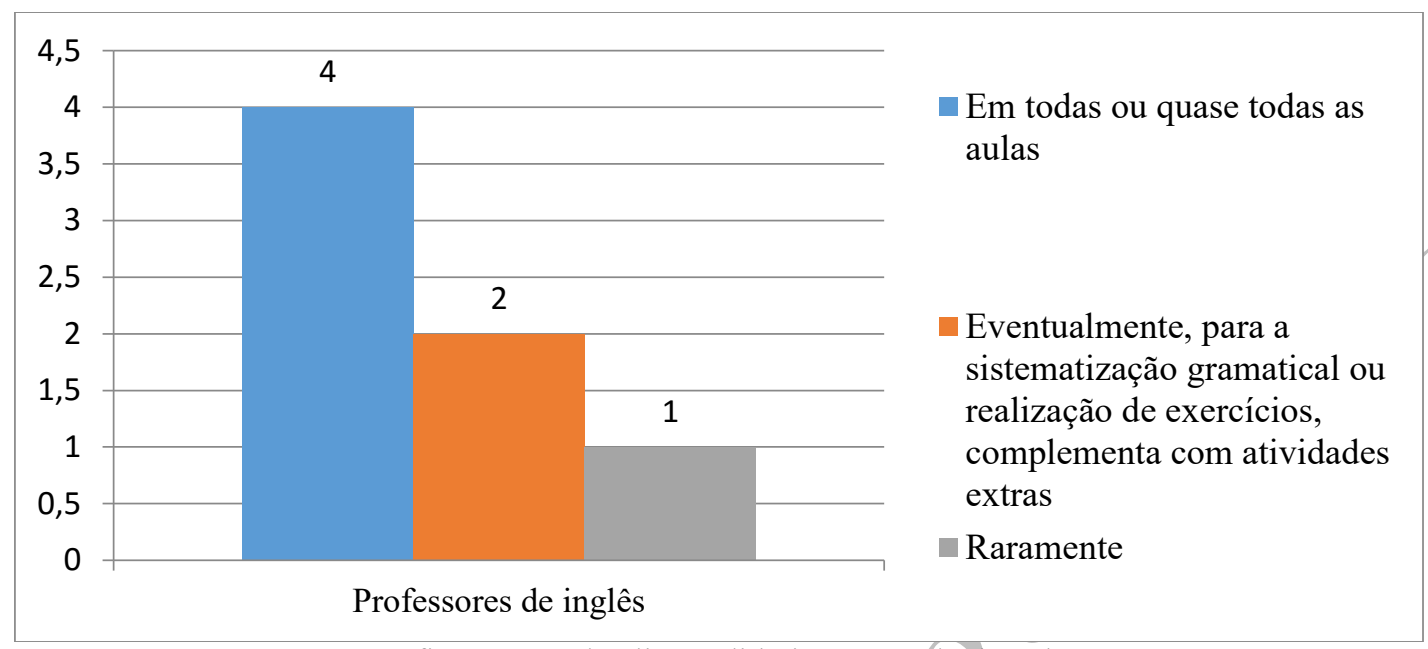

Gráfico 1. Uso dos livros didáticos em sala de aula.

A seguir, são apresentados excertos das entrevistas com os professores, com relação ao uso do livro didático. Lembramos que a análise das respostas às entrevistas foi realizada com base na identificação de elementos ricos em significação (BARTON, 2004) para cada pergunta feita, a partir de uma interpretação semântico-funcional, não lexicogramatical. Em outras palavras, a análise identifica segmentos que trazem significados relevantes com base no contexto de cada pergunta.

No caso da pergunta relacionada à frequência de uso do livro didático em sala de aula, elementos ricos em significação são aqueles que indicam frequência, tais como "diariamente", "sempre", "em raríssimos momentos" nos exemplos a seguir.

PI25 - "eu uso o livro didático diariamente, principalmente porque, como é ensino médio, que tem um período, 45 minutos por semana, é bem complicado assim, essa questão do tempo, assim, interfere muito, então eu prefiro usar livro didático"

PI3 - "não sempre, ah, a gente tenta complementar sempre a questão dos conteúdos, no caso, os esquemas do livro normalmente não estão assim muito completos, alguma coisa sempre tem que acrescentar. Mas, no mais, os textos, aí a gente utiliza porque é o material deles né, dos alunos"

PI4 - “em raríssimos momentos, (...) eu optei por utilizar material próprio até porque eu fiz uma investigação com os alunos primeiro, observei o que eles já

\footnotetext{
${ }^{5}$ Os professores entrevistados são identificados no decorrer do texto a partir da abreviação PI (professor de inglês). Os números são utilizados para individualizar cada professor.
} 
tinham de conhecimento (...). Outra característica que acabou determinando foi a situação do material didático não ser disponibilizado para o aluno, ficar com ele, ter uma relação mais próxima com ele, é pra ele utilizar, não pode escrever, tem que devolver"

Segundo as entrevistas, para alguns professores o livro didático parece cumprir um papel central, mas também é visto como um recurso utilizado para suprir a falta de tempo (PI2), e para outros ainda, o livro didático parece ser visto como acessório, para complementar as aulas (PI3, PI4).

Ressaltamos, contudo, o caso de PI4, que destaca o uso do seu próprio materialdidático, apesar de afirmar que utiliza o livro didático em "raríssimos momentos". Uma das razões pelas quais o professor PI4 não utiliza o livro didático de inglês frequentemente na escola em que trabalha é a impossibilidade de o aluno escrever no livro. Segundo a professora, os alunos teriam uma relação "mais próxima" com o livro se pudessem completar as respostas das atividades no próprio material.

Entre outras adversidades, outros professores entrevistados ainda relatam que muitas vezes não há número suficiente de livro didáticos (disponibilizados pelo PNLD e selecionados pelos professores) para todos os alunos, sendo assim, o professor seleciona um livro didático já disponível no acervo da escola, combina diferentes materiais, os adaptando para as aulas, ou ainda produz seu próprio material didático, como é o caso de PI4.

Percebemos que problemas na distribuição e no acesso aos livros didáticos podem impossibilitar/dificultar o uso dos livros pelos professores, porém, o conteúdo dos livros didáticos também pode influenciar o uso ou complementação desse material, como observado nas respostas dos professores. O professor PI3 explica que o livro didático precisa ser complementado, que não dá conta de alguns conteúdos. O professor PI4 corrobora essa ideia e salienta a importância de considerar o interesse do seu público-alvo, sendo um dos motivos pelos quais utiliza o livro didático em "raríssimos momentos". O professor PI4 reconhece que algumas vezes o livro didático não dá conta das necessidades do contexto situado de ensino, sendo necessária uma investigação a fim de identificar esses interesses e produzir ou adaptar o material de acordo com as necessidades daqueles alunos.

Percebemos que as razões para a adoção ou não de livros didáticos pelos professores refletem as vantagens e desvantagens citadas por Ramos (2009). Entre as vantagens de adotar um livro didático se encontram a questão do tempo que o professor precisaria para preparar seu próprio material, como proposto por PI3, e a continuidade oferecida pelo livro didático, 
auxiliando o professor na sequência de aula, ou seja, "o livro didático fornece conteúdos, textos e atividades que delineiam muito do que acontece em sala de aula" (RAMOS, 2009, p. 173); porém entre as desvantagens estariam as limitações do livro didático em termos de que “"engessa' o que deve acontecer em sala de aula” (RAMOS, 2009, p. 173), podendo não dar conta das necessidades dos alunos, sendo necessário que o professor adapte esse material ou produza o seu próprio.

Uma das questões que pode influenciar a escolha e a adoção de um livro didático é o modo como os recursos semióticos visuais são abordados. Porém, essa seleção vai depender de como o professor entende o papel da linguagem visual nos livros, que é o segundo tópico abordado na entrevista, Avaliação do papel da linguagem visual no ensino de inglês.

As respostas dos professores sugerem que todos consideram relevante/importante considerar a linguagem visual, por diferentes razões, destacadas no Gráfico 2.

Gráfico 2. Avaliação do papel da linguagem visual no ensino de inglês.

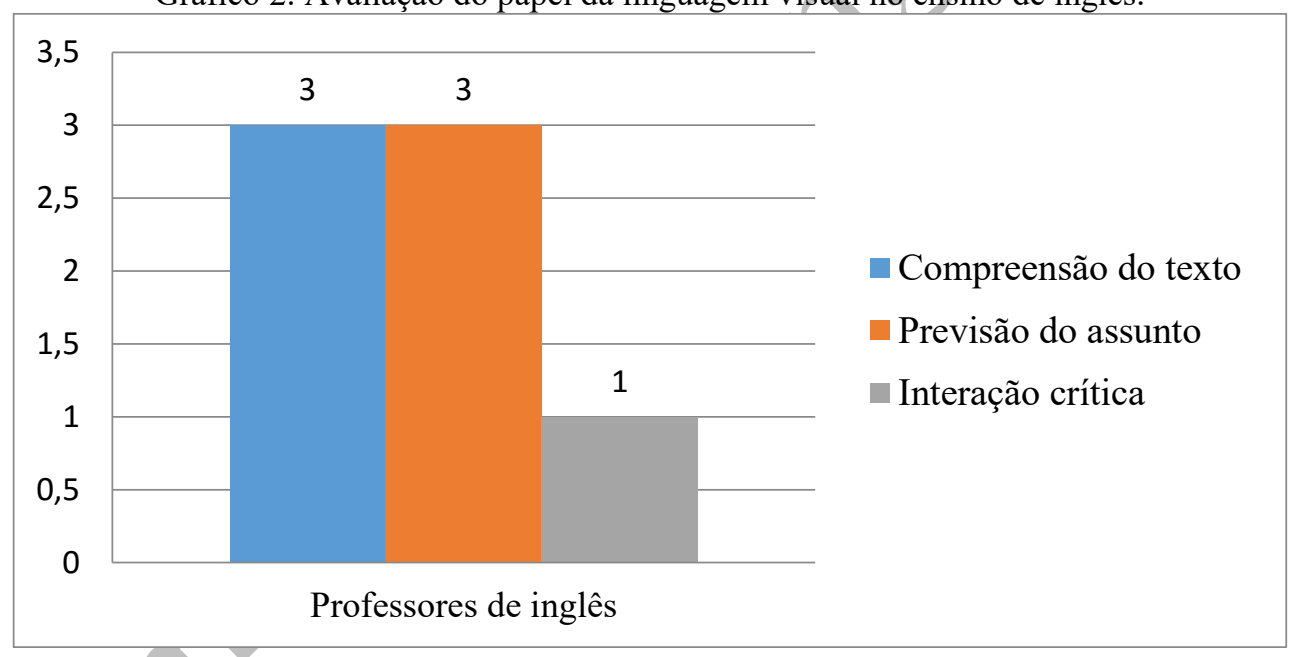

Como podemos ver no Gráfico 2, o mesmo número de professores explicita duas razões principais para a relevância de considerar a linguagem visual em sala de aula, a previsão do assunto do texto e a compreensão do texto. Abaixo, seguem alguns excertos das respostas dos professores.

Previsão do assunto do texto

PI1 - "muito importante, porque a partir dali eu vou fazer os questionamentos, pra saber se eles entenderam ou não. Então, assim ó, por exemplo, aqui ó, pega o texto e daí tu vê a imagem, o que te remete essa imagem, deem uma olhadinha no título, o que vocês acham, sobre o que o texto vai falar" 


\section{Compreensão do texto}

PI5 - "é bastante importante, até por ser a língua inglesa, no caso, eu converso bastante com os alunos que quando eles não conseguem identificar muitas coisas pelos textos, eles vão pelas próprias ilustrações (...), pra identificar muitas coisas ahm..no próprio vocabulário, pra, que ajuda bastante no próprio vocabulário deles"

PI1 argumenta a importância de observar os recursos semióticos visuais em aula com base na possibilidade de prever o assunto do texto, a partir destes. A pré-leitura, um dos estágios de uma aula de leitura, tem como um de seus objetivos "o ativamento de conhecimento prévio" do aluno sobre o assunto do texto (MOTTA-ROTH, 2008b, p. 245) e isso pode ser realizado por meio da observação/análise dos recursos semióticos visuais que o texto apresenta (MOTTA-ROTH, 2008b). Essa função, de prever o assunto do texto por meio de recursos semióticos visuais, é importante em uma aula de língua estrangeira visto a possibilidade de o aluno se familiarizar com o texto, mesmo sem conhecer a língua-alvo.

Para identificar o assunto do texto, podemos partir do reconhecimento de significados produzidos por elementos do contexto de situação, como os participantes envolvidos na situação representada e a natureza de seus papeis, por exemplo (FUZER; CABRAL, 2014). Contudo, esse reconhecimento também pode se dar no momento da leitura propriamente dita, da aula de leitura (MOTTA-ROTH, 2008b). Sendo assim, ao passo que os recursos semióticos visuais podem certamente servir para ativar o conhecimento prévio dos alunos sobre determinada temática, justamente em função da especialização funcional (KRESS, 1997) desses recursos de concentrarem informações em uma lógica espacial, que permite acesso rápido ao conteúdo proposicional, também podem servir para outros propósitos. Dentre esses propósitos, citamos como exemplo, a compreensão do texto como um todo. Sendo assim, podemos dizer que os recursos semióticos visuais são essenciais e capazes de cumprir diferentes funções nos textos.

Desse modo, a segunda justificativa apontada pelos professores, Compreensão do texto, parece ampliar a ideia da previsão do assunto do texto para a compreensão do texto como um todo. Entretanto, essa ideia é limitada aos recursos semióticos visuais como acessórios/apoio para entender o léxico do recurso semiótico verbal escrito (vocabulário, como citado por PI5 e pela maioria dos professores entrevistados), no nível da lexicogramática. Jewitt e Kress (2003) destacam a necessidade de considerar, no letramento multimodal, todos os recursos semióticos (verbais, visuais, sonoros e etc.) que constituem determinado texto como igualmente 
significativos e, acrescentamos que, essa consideração deve contemplar todos os estratos da linguagem (lexicogramática, semântica e pragmática, contexto de situação, contexto de cultura, ideologia), considerando os diferentes conhecimentos de LMC.

Apenas um dos professores de inglês se refere à interação crítica do aluno como uma razão para se considerar os recursos semióticos visuais. Desse modo, podemos dizer que esse professor reconhece a necessidade de não apenas entender os significados dos recursos semióticos visuais nos textos, mas entender seu papel no contexto, ou seja, na representação de diferentes visões de mundo, por exemplo. Precisamos, no entanto, fazer uma observação sobre esse professor. Ele é colega da pesquisadora, tendo familiaridade com a pesquisa e, portanto, suas respostas podem estar influenciadas por esta familiaridade, indo de encontro com a proposta deste trabalho.

Com relação aos gêneros citados pelos professores, verificamos uma grande diversidade. Eles citam gêneros como notícias, reportagens, poemas, gráficos, folders de turismo, perfil do Facebook, carta, e-mail, bilhete, cartazes, charges, contos, histórias. Uma das razões para essa diversidade é a possibilidade de ensinar linguagem utilizando diferentes gêneros de diferentes áreas. Se observarmos, por exemplo, a organização geral de livros didáticos de inglês identificamos essa possibilidade uma vez que os livros didáticos são constituídos de unidades e cada unidade inclui gêneros diferentes para o estudo da linguagem.

A fim de verificar, então, como os professores abordam os recursos semióticos visuais presentes nos gêneros que trabalham em sala de aula, solicitamos que explicitassem exemplos de tipos de atividades e de perguntas que propõem aos alunos e que façam referência a recursos semióticos visuais. No Quadro 3, verificamos as respostas dos professores com base no plano de estratificação da linguagem, discutido no Capítulo 2.

A partir do Quadro 3, verificamos que as atividades e perguntas propostas pelos professores de inglês contemplam a maioria dos estratos, uma vez que o objetivo da área é desenvolver diferentes habilidades/conhecimentos por meio de gêneros introduzidos em aula. Com base no Quadro 3, podemos dizer que os professores enfocam em conhecimentos relacionados ao estrato da lexicogramática, ou seja, na identificação de participantes “objetos" (PI5), circunstâncias "locais" (PI5), no reconhecimento do tipo de contato ou não entre participantes representados e o público-alvo "pra onde o participante está olhando" (PI7). Os professores também enfocam o estrato da semântica e pragmática que diz respeito à compreensão do meio (metafunção ideacional/representacional) (FUZER; CABRAL, 2014, p. 
32), nos exemplos "Sobre o que vai falar" (PI1, PI2); à relação com outros participantes (metafunção interpessoal/interativa) (FUZER; CABRAL, 2014, p. 32), nos exemplos, “Quem é essa pessoa?". A organização da informação (metafunção textual/composicional) (FUZER; CABRAL, 2014, p. 32) não foi enfocada pelos professores.

Quadro 3. Tipos de atividades e perguntas propostas pelos professores classificadas conforme os estratos da linguagem.

\begin{tabular}{|c|c|c|c|c|c|c|}
\hline & $\begin{array}{c}\text { Grafologia } \\
\text { /fonologia/ } \\
\text { gráfico }\end{array}$ & $\begin{array}{c}\text { Lexicogramátic } \\
\text { a }\end{array}$ & $\begin{array}{l}\text { Semântica e } \\
\text { pragmática }\end{array}$ & Registro & Gênero & Ideologia \\
\hline PI & - & $\begin{array}{l}\text { Locais, cores, } \\
\text { objetos (PI5) } \\
\text { "Questão de } \\
\text { vetores- pra } \\
\text { onde o } \\
\text { participante } \\
\text { está olhando" } \\
\text { (PI7) } \\
\text { Trabalho com } \\
\text { vocabulário } \\
\text { (PI4) }\end{array}$ & $\begin{array}{c}\text { “Quem é essa } \\
\text { pessoa?” (PI1, } \\
\text { PI2, PI4) } \\
\text { "Vocês } \\
\text { conhecem?” (PI2, } \\
\text { PI4) } \\
\text { "Sobre o que vai } \\
\text { falar” (PI1, PI2) } \\
\text { “O que veem na } \\
\text { imagem” (PI3) }\end{array}$ & $\begin{array}{c}\text { “Quem é essa } \\
\text { pessoa?" (PI1, PI2, } \\
\text { PI4) } \\
\text { "Vocês conhecem?" } \\
\text { (PI2, PI4) } \\
\text { “Sobre o que vai } \\
\text { falar" (PI1, PI2) } \\
\text { "O que veem na } \\
\text { imagem" (PI3) } \\
\text { "De onde foi tirado o } \\
\text { texto?" (PI2, PI7) }\end{array}$ & $\begin{array}{l}\text { Identificar } \\
\text { o texto } \\
\text { (PI3) } \\
\text { "Já viram } \\
\text { essa } \\
\text { imagem } \\
\text { em algum } \\
\text { lugar?" } \\
\text { (PI1, PI2) }\end{array}$ & $\begin{array}{l}\text { Opiniões } \\
\text { dos alunos } \\
\text { (PI4) } \\
\text { Como } \\
\text { representa } \\
\text { ria de } \\
\text { outra } \\
\text { forma } \\
\text { (PI6) }\end{array}$ \\
\hline
\end{tabular}

Os exemplos de atividades citadas pelos professores que contemplam o estrato da semântica e pragmática se repetem no estrato do registro, visto que ambos os estratos servem para responder essas questões.

O registro está relacionado ao contexto de situação, "o ambiente imediato no qual o texto está de fato funcionando" (FUZER; CABRAL, 2014, p. 27). Das três variáveis do contexto de situação, as atividades sugeridas pelos professores de inglês contemplam o campo, "a atividade que está sendo realizada" (FUZER; CABRAL, 2014, p. 30), nos exemplos: "Sobre o que vai falar" (PI1, PI2), “Já viram essa imagem em algum lugar?” (PI1, PI2), “O que veem na imagem"(PI3), e a variável das relações, que compreende os participantes envolvidos, "a natureza dos papeis que desempenham, o grau de controle de um participante sobre o outro, a relação entre eles (...) e a distância social ou grau de formalidade“ (FUZER; CABRAL, 2014, p. 30), nos exemplos: “Quem é essa pessoa?” (PI1, PI2, PI4), "Vocês conhecem?” (PI2, PI4). A variável modo não foi contemplada.

Com relação ao gênero, duas atividades abrangem esse estrato, "Identificar o texto" (PI3) e "já viram essa imagem em algum lugar?” (PI1; PI2). O gênero faz parte do contexto de cultura, que "se constitui de práticas, valores e crenças mais recorrentes que permanecem ao longo do tempo numa comunidade e são compartilhados no grupo social" (FUZER; CABRAL, 
2014, p. 29). A resolução de uma das atividades, portanto, requer, explicitamente, que o aluno identifique o gênero estudado na aula de acordo com as características recorrentes desse gênero, já a outra atividade solicita que o aluno verifique a possibilidade de já ter visto uma imagem, a qual pode ser recorrente em outro gênero ou outro exemplar do gênero estudado, por exemplo.

Outro estrato abarcado pelas atividades propostas pelos professores de inglês é o da ideologia. Ao solicitar "Opiniões dos alunos" (PI4) e "Como representaria de outra forma" (PI6), ambas as atividades sugeridas pelos professores de inglês direcionam para uma discussão sobre a desnaturalização dos pontos de vista representados nos textos (MOTTA-ROTH, 2008a) por meio da reflexão dos alunos.

Nenhuma das atividades sugeridas pelos professores enfoca explicitamente conhecimentos de LMC relacionados especificamente ao estrato da grafologia/gráfico, talvez por esse estrato enfocar uma unidade semiótica minúscula demais para as finalidades do contexto escolar na disciplina de inglês. Indiretamente, entretanto, podemos considerar que esse estrato é explorado, uma vez que materializa os demais estratos.

Com relação ao conceito de LMC, a pergunta da entrevista era a seguinte: "Você conhece o conceito de letramento multimodal e/ou visual? Em caso afirmativo, como você explicaria o que significa?". Na época da entrevista, optamos em sugerir os conceitos de letramento multimodal ou letramento visual em vista da possibilidade de o professor já ter ouvido/estudado pelo menos um dos dois conceitos, dado que o conceito de LMC ainda é recente. O Gráfico 3 apresenta os resultados dessa pergunta da entrevista.

Gráfico 3. Conceitos de letramento multimodal/letramento visual sugeridos pelos professores.

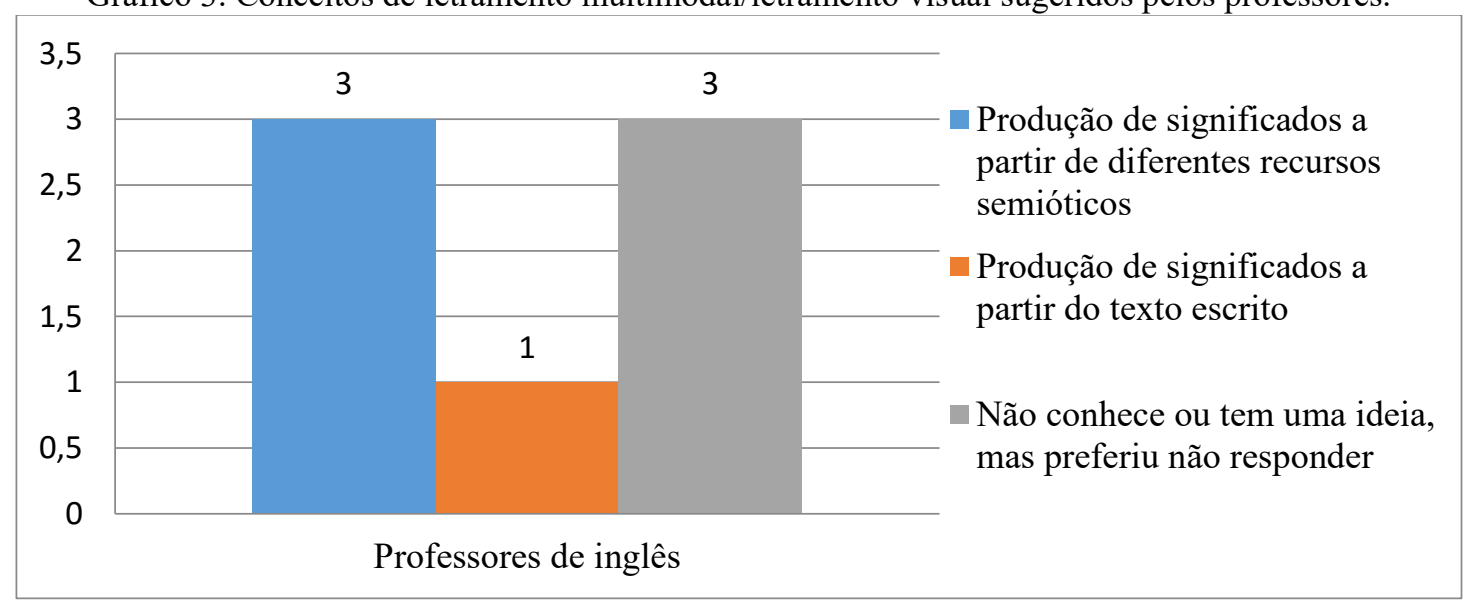


Conforme as respostas dos professores, chegamos a duas definições para o conceito solicitado na entrevista, como podemos ver no Gráfico 3. Essas definições variam entre os professores. Porém, a quantidade de professores que não conhece ou preferiu não responder à pergunta da entrevista é grande, quase metade dos professores. Além disso, mesmo alguns dos professores que responderam à pergunta e que tentaram definir o conceito, admitiram a dificuldade em defini-lo, como PI4.

PI4 - "Esse conceito multimodal é mais novo, né, (...). Eu já li, mas não saberia te dizer agora quais são os termos mais adequados sobre ele, já ouvi falar, mas sei que é um termo que vem novo a partir do que, de que a gente tá num mundo bastante visual, né, de imagens. Imagens tão sendo muito mais exploradas que os textos escritos, né os textos verbais. Então, a princípio eu acho que, não sei exatamente se é isso, mas acho que não mudou muita coisa. Acho que mudou a terminologia, de repente. A ideia, aquela bem básica de que da exploração da imagem para produzir alguns sentidos, acho que permaneceu."

Percebemos que apesar da dificuldade em definir letramento multimodal, PI4 entende que a imagem seria um dos recursos para produzir significados, "exploração da imagem para produzir alguns sentidos". O comentário de PI4 é um exemplo de resposta que define letramento multimodal ou letramento visual como "Produção de significados a partir de diferentes recursos semióticos", no Gráfico 3.

Com relação a outras definições, o professor PI1, relaciona o conceito de letramento multimodal com o texto escrito, por exemplo.

PI1 - Nunca ouvi falar, letramento multimodal não, o visual acredito que seja a partir das das, por exemplo, algumas letras que procuram identificar alguma coisa (...).

PI1 admite que não conhece os conceitos solicitados na pergunta da entrevista, apesar disso, tenta definir. Sua definição, contudo, está relacionada ao texto escrito, como em "letras que procuram identificar alguma coisa”. Esse exemplo reflete os muitos anos em que a linguagem verbal escrita era reconhecida como o principal recurso semiótico de um gênero. Contudo, como explicam Jewitt e Kress (2003), diversos recursos semióticos podem ser utilizados para a construção de significado de um texto e todos esses precisam ser considerados com o mesmo grau de importância dos recursos semióticos verbais escritos. 
A partir das definições sugeridas pelos professores, observamos que, apesar da maioria deles não conhecer os conceitos solicitados na entrevista, alguns tentam construir uma definição. As definições propostas pelos professores, com exceção da definição de PI1 e daqueles que preferiram não responder, se aproximam da concepção de Cope e Kalantzis (2000) de que letramento multimodal envolveria saberes/conhecimentos para mobilizar diferentes recursos semióticos em um texto para a produção de significados. Contudo, como discutimos na Introdução e na seção de Pressupostos Teóricos deste trabalho, a definição de letramento multimodal ainda envolve a habilidade de interagir discursiva e criticamente em variados contextos, por isso adotamos a terminologia de letramento multimodal crítico neste trabalho. Com base nas respostas das entrevistas, muitos dos professores demonstram entender essa relação de recursos semióticos para a produção de significados, entretanto, apesar de citar algumas atividades que remetem ao estrato do discurso, professores parecem não reconhecer explicitamente o elemento crítico do LMC, visto que não mencionaram na definição do conceito.

O elemento crítico do LMC pode não ser mencionado nas definições sugeridas pelos professores para a entrevista visto que propomos a definição do conceito de "letramento multimodal/letramento visual", sem o item/lexical "crítico". O conceito de LMC ainda é recente, por isso não questionamos os professores usando essa nomenclatura. Contudo, uma vez que a maioria dos professores não conhecia o conceito de "letramento multimodal/letramento visual', como vimos nos excertos das entrevistas, os professores tentaram criar uma definição com base no item lexical "visual" e com base na contextualização da autora sobre o trabalho antes da entrevista. Sendo assim, presumimos que se tivéssemos sugerido que os professores definissem "letramento multimodal crítico", com a inclusão do item lexical "crítico", as suas definições talvez contemplassem esse elemento.

Nesse sentido, o resultado das definições dos professores e os resultados gerais deste estudo indicam o reconhecimento por parte dos professores sobre a diversidade de recursos semióticos que constituem os gêneros, porém muitas vezes parecem não possuir ferramentas conceituais e metalinguísticas suficientes para abordar esses recursos de forma a desenvolver conhecimentos de LMC. Em outras palavras, podemos dizer que, apesar dos diversos estudos já mencionados neste trabalho sobre multimodalidade e conhecimentos de LMC, os pressupostos desse conceito ainda são pouco recontextualizados na escola, conforme as respostas das entrevistas com os professores sugerem. Uma das razões para isso pode ser o 
recente interesse na natureza multimodal dos gêneros no contexto brasileiro, que parece estar, aos poucos, ganhando espaço no contexto escolar.

Essas generalizações são feitas com base nos resultados das entrevistas, sendo assim, precisamos salientar que não sabemos como os professores abordam os recursos semióticos visuais na prática de sala de aula. Ressaltamos a possibilidade de que os professores desenvolvam conhecimentos de LMC, como vimos nas atividades propostas pelos professores, podendo não ter mencionado explicitamente nas entrevistas.

As entrevistas, portanto, serviram para entender como professores de inglês recontextualizam conhecimentos de LMC. Essa verificação é importante a fim de possibilitar reflexões sobre propostas com relação à inclusão/recontextualização desse conceito na sala de aula, corroborando para o desenvolvimento de conhecimentos de LMC no contexto escolar e, assim, para uma participação bem-sucedida de estudantes na sociedade em que vivem.

\section{Considerações finais}

Como explicamos no decorrer deste trabalho, notamos as crescentes mudanças nos gêneros em termos de um aumento na inclusão de recursos semióticos visuais (KRESS; VAN LEEUWEN, 2006), o que cria a necessidade de desenvolver conhecimentos sobre os diferentes recursos semióticos que constituem os gếneros, ou seja, conhecimentos de LMC. Neste trabalho, entendemos que o conceito de LMC diz respeito à saberes de reconhecimento e produção de gêneros utilizando diferentes recursos semióticos, a partir dos diferentes estratos da linguagem, mobilizados em qualquer interação discursiva (MEURER, 2011).

A fim de verificar como esse conceito é abordado na escola, no presente trabalho, investigamos discursos de professores de inglês a partir de entrevistas. Os resultados apontam que o conceito de LMC é, de certa forma, recontextualizado na escola. Identificamos isso por meio do reconhecimento dos professores da importância de considerar os diferentes recursos semióticos, por meio das atividades propostas pelos professores as quais contemplam os diferentes estratos da linguagem e por meio das definições propostas pelos professores. Contudo, verificamos que as definições do conceito de LMC propostas pelos professores refletem um distanciamento do elemento crítico do conceito.

Neste sentido, destacamos que as OCNs (BRASIL, 2006) propõem que os conhecimentos desenvolvidos em sala de aula não deveriam estar atrelados apenas ao conteúdo proposicional da área, mas deveriam estar a serviço de uma participação informada do aluno na 
sociedade. Frente a isso, propomos uma abordagem "intervencionista e emancipador[a]" (MOTTA-ROTH, 2008b, p. 362) de LMC, para que o professor reflexivo possa guiar e possibilitar ao estudante conhecimentos para a articulação de diversos recursos semióticos em gêneros específicos a contextos situados de maneira crítica e reflexiva.

\section{Referências Bibliográficas}

AGA, G. Upgrade your English 1. 1. ed. São Paulo: Richmond, 2010.

BARTON, E. Linguistic Discourse Analysis: How the Language in Text Works. In: BAZERMAN, C.; PRIOR, P. (Ed.). What Writing Does and How It Does It: An introduction to Analyzing Texts and Textual Practices. New Jersey: Lawrence Erlbaum Associates, 2004. p. $57-82$.

BEZEMER, J.; KRESS, G. Changing Text: A Social Semiotic Analysis of Textbooks. Designs for Learning, v. 3, n. 1-2. p. 10-29, 2010. crossref http://dx.doi. org/10.16993/dfl.26

BRASIL. MEC/SEC. Orientações curriculares para o ensino médio - Linguagens, Códigos e suas Tecnologias. v. 1. Brasília: MEC/SEC, 2006. Disponível em: http://portal.mec.gov.br/seb/arquivos/pdf/book volume 01 internet.pdf. Acesso em: 10 mai. 2012.

. Programa Nacional do Livro Didático. Portal do Ministério da Educação. Brasília: $\mathrm{MEC} / \mathrm{SEF}$. Disponível em: http://portal.mec.gov.br/index.php? Itemid $=668 \mathrm{id}=12391$ option $=$ com contentview $=$ article. Acesso em: 04 junho 2014.

CATTO, N. R. Letramento multimodal: participação em gêneros discursivos multimodais em livros didáticos de língua inglesa. Pesquisas em Discurso Pedagógico. v. 1, 2014.

CERVETTI, G.; PARDALES, M. J.; DAMICO, J. S. A tale of differences: comparing the traditions, perspectives and educational goals of critical reading and critical literacy. Reading Online, v. 4, n. 9, 2001. Disponível em: http://www.readingonline.org/articles/cervetti/. Acesso em: 13 set. 2014.

COPE, B.; KALANTZIS, M. Introduction. Multiliteracies: the beginning of an idea. In: COPE, B.; KALANTZIS, M. (Ed.). Multiliteracies: literacy learning and the design of social futures. London: Routledge, 2000. p. $3-8$.

FAIRCLOUGH, N. Discourse and Social Change. Cambridge: Polity Press. 1992.

. Analysing Discourse: textual analysis for social research. London: Routledge. 2003. 
FLOREK, C. S. Uma análise crítica de gênero de resumos acadêmicos gráficos. 2015. 238f. Dissertação (Mestrado em Letras). Universidade Federal de Santa Maria, Santa Maria, 2015.

FUZER, C.; CABRAL, S. R. S. Introdução à Gramática Sistêmico-Funcional em Língua Portuguesa. Campinas, SP: Mercado das Letras. 2014.

HALLIDAY, M. A. K.; HASAN, R. Language, context, and text: Aspects of language in a social-semiotic perspective. Oxford: Oxford University Press. 1989. 1994.

.; MATHIESSEN, C. An introduction to functional grammar. 1. ed. London: Arnold.

. An introduction to functional grammar. 4. ed. London: Arnold. 2014.

HEMAIS, B. J. W. Gêneros discursivos e multimodalidade: desafios, reflexões e propostas no ensino de inglês. Campinas, SP: Pontes Editores. 2015.

HENDGES, G. R. Gramática da imagem: modalidades semióticas não-verbais em artigos acadêmicos de linguística. In: MOTTA-ROTH, D.; BARROS, N. C.; RICHTER, M. G. (Orgs.) Linguagem Cultura e Sociedade. Porto Alegre: Editora e Gráfica Eficiência Ltda. 2006. p. 23 -38 .

JEWITT, C. Different approaches to multimodality. In:

(Ed.). The Routledge Handbook of Multimodal Analysis. 2. ed. New York: Routledge. 2011 . p. 28 - 39.

; KRESS, G. Multimodal literacy. New York: Peter Lang Publishing, 2003.

KRESS, G. Visual and verbal modes of representation in electronically mediated communication: the potential of new forms of text. In: SNYDER, I. Page to screen: taking literacy into the electronic era. London: Routledge. 1997, p. 53-79.

What is mode. In: JEWITT, C. (Ed.). The Routledge Handbook of Multimodal Analysis. 2. ed. New York: Routledge, 2011. p. 54 - 67.

; VAN LEEUWEN. T. Reading Images: The Grammar of Visual Design. 2. ed. London: Routledge, 2006.

KUMMER, D. A. Letramento multimodal crítico: sob a perspectiva de livros didáticos e professores de inglês e de biologia. 2015. 149f. Dissertação (Mestrado em Letras). Universidade Federal de Santa Maria, Santa Maria, 2015.

MARQUES, P. M. Promovendo o letramento visual a partir do gênero discursivo notícia de popularização da ciência. 2015. 130f. Dissertação (Mestrado em Letras). Universidade Federal de Santa Maria, Santa Maria, 2015.

MEURER, J. L. Integrando estudos de gêneros textuais ao contexto de cultura. In: KAWORSKY, A. M.; GAYDECZKA, B.; BRITO, K. S. (Orgs.). Gêneros textuais: reflexões e ensino. 4. ed. São Paulo: Parábola Editorial. 2011, p. 175-196. 
MOTTA-ROTH, D. Análise crítica de gêneros: contribuições para o ensino e a pesquisa de linguagem. D.E.L.T.A, v. 24, n. 2, p. 341-383, 2008a. crossref http://dx.doi.org/10.1590/s0102-44502008000200007

. Para ligar a teoria à prática. In: MOTTA-ROTH, D.; CABAÑAS, T.; HENDGES, G. R. (Orgs.). Análises de textos e de discursos: relações entre teorias e práticas. Santa Maria, RS: Editora do PPGL, 2008b, p. 243-272.

Sistemas de gênero e recontextualização da ciência na mídia eletrônica. Revista Gragoatá. n. 28, p. 153-174, 2010.

Questões de metodologia em análise de gêneros. In: KAWORSKY, A. M.; GAYDECZKA, B.; BRITO, K. S. (Orgs.). Gêneros textuais: reflexões e ensino. 4. ed. São Paulo: Parábola Editorial. 2011, p. 153-174.

NASCIMENTO, R. G. Research genres and multiliteracies: channelling the audience's gaze in powerpoint presentations. 2012, 231f. Tese (Doutorado em Letras). Universidade Federal de Santa Catarina: Santa Catarina. 2012.

PREDEBON, N. R. C. Do entretenimento à crítica: letramento multimodal crítico no livro didático de inglês com base em gêneros dos quadrinhos. 2015, 241f. Tese (Doutorado em Letras). Universidade Federal de Santa Maria: Santa Maria. 2015.

RAMOS, R. C. G. O livro didático de língua inglesa para o ensino fundamental e médio: papéis, avaliação e potencialidades. In: DIAS, R.; CRISTOVÃO, V. L. L. (Org.). O livro didático de língua estrangeira: múltiplas perspectivas. Campinas, SP: Mercado de Letras, 2009. p.173198.

SCHERER, A. S. Engajamento e efeito de monologismo no gênero notícia de popularização científica. 2013, 167f. Dissertação (Mestrado em Letras). Universidade Federal de Santa Maria: Santa Maria. 2013.

SWALES, J. Genre analysis: English in academic and research settings. Cambridge: Cambridge University Press. 1990.

THE NEW LONDON GROUP. A pedagogy of multiliteracies: designing social futures. The Harvard Educational Review, v. 1, n. 66, p. 60-92, 1996.

. A pedagogy of multiliteracies: designing social futures. In: COPE, B.; KALANTZIS, M. Multiliteracies: Literacy learning and the design of social futures. London: Routledge. 2000, p. 9-37.

TICKS, L. K. Contribuições da análise de gênero para o estudo de conceitos de linguagem em livros didáticos e no discurso de professoras de inglês. 2003. 160f. Dissertação (Mestrado em Letras). Universidade Federal de Santa Maria, Santa Maria. 2003. 
UNIVERSIDADE FEDERAL DE SANTA MARIA. Comitê de Ética em Pesquisa da Universidade Federal de Santa Maria. Santa Maria. Disponível em < http://coral.ufsm.br/cep/>. Acesso em 22 abril 2014.

VAN LEEUWEN, T. Genre. In: Van LEEUWEN, T. Introducing Social Semiotics. London: Routledge. 2005, p. 117-138. 